\title{
Reevaluation of the Egyptian code of housing and energy consumption with emphasis on shading devices rotation angles
}

\author{
Tarek M. Kamel \\ Department of Architecture \& Environmental Design, Arab Academy for Science \& Technology, Sheraton, Cairo, Egypt \\ Corresponding Author: tkamel@aast.edu
}

Submitted :02/09/2020

Revised : :15/12/2020

Accepted : 26/12/2020

\begin{abstract}
The passive system technique is dynamically used as an alternative to the active system, in order to minimize the peak loads and the total EUI in $\mathrm{kWh} / \mathrm{m}^{2}$ for any building prototype. Sun breaker or shading device is a basic traditional method and Mashrabiya was previously used for privacy. It reduces the heat gained and emitted from sun`s rays, in addition to the fabricated wood material and its specs of bad conductor. The study aims at investigating the effect of rotational shading devices around the Y-axis. Will the rotation have a significant impact on the EUI or not? The research methodology is built upon generative modeling tool of parametric design, Rhinoceros Version 6.0, with the cooperation of Grasshopper, Ladybug and Honeybee, and Toolbox. Five hundred running simulations are carried out to determine the optimal angle of rotation with maximum reduction in cooling loads, and the interpretation is $30^{\circ}$. Two linear regression equations are derived from this valuable study to deduce the correlation between independent and dependent variables when the sun breaker material is matt or reflective and to know how the total EUI $\mathrm{kWh} / \mathrm{m}^{2}$ can be minimized.
\end{abstract}

Keywords: EUI; Parametric tool; Shading devices.

\section{INTRODUCTION}

Corona virus or COVID-19 is one of the pandemics that is widely spread all over the world with daily increases in number of infected people. Unfortunately, COVID-19 has had several bad side effects on the economic market, health industry, and so on. However, it has one positive effect, which is attributed to environmental considerations: the climatic conditions, the reduction of carbon dioxide pollution, the healing of the zone hole, the restoration of biodiversity to nature, and the equilibrium of habitats (Deutsche Welle, 2020; The British Broadcasting, 2020; Carbon Brief, 2020)

Energy crisis is one of the main challenges facing the world today (Booth et al. 2015). A direct correlation is established between energy efficiency and occupant satisfaction to ensure good thermal comfort and better outdoor vision (Lagois et al., 2014). Physiological effects may have an impact on human occupants due to the amount and quality of daylight that can reach indoor spaces (USGBC2014). This is not all, but the more the exposure to ample 
sunshine, the less the healing time in hospitals, the greater the student's success and mood during the school days, the higher the efficiency of office work, and the greater the battle against depression and lethargy (Li and Tsang, 2008).

Sun breaker is an external shading device, typically used to reduce the heat emitted from sun`s rays or to reduce the cooling loads of the building usage by $23-89 \%$ as deduced by Dubois (Dubois, 1997). But the reduction depends on shading fabricated material, climatic conditions, building orientation, and so on.

The architect is the maestro of the building engineers' plateau. He is the one responsible for building design and plan prototypes of every particular building. Shading devices may usually be constructed using the conventional approach widely used by the solar path (Marsh, 2003) or the shading mask (Olgyay, 1957). But often they easily lose adequate precision, and the desired results are not satisfactory when compared objectively to software calculations.

\section{RESEARCH BACKGROUND AND OBJECTIVE}

Nowadays in stylish, contemporary housing, typically architects ignore the role of shading devices, which are the most essential elements of the facade but are instead used like plaster cornice, which has no purpose whatsoever. Shading devices have many functions. They can either block or mitigate the energy emitted by the sun's rays. Otherwise, they can incorporate esthetic and identification to the facade using horizontal or vertical louvers or combined.

The main objective of this study is to improve the local national energy usage code for residential buildings in Egypt, where the climatic condition is known. There is a high tropical and subtropical zone, and special environmental solutions and aspects were required to overcome undesirable sun's rays and to reduce the cooling load. The study comes with two distinct equations, which can aid the architects during the early design phases. The two equations are mainly based on independent variables which are the WWR\%, angle of rotation around Y-axis, shading depth, and finally the light intensity, while the dependent variable is the total EUI in $\mathrm{kWh} / \mathrm{m}^{2}$. In the Grasshopper script, batteries input data for the R-values: walls, roof, floor, and windows glass Solar Heat Gain Coefficient (SHGC), are constant throughout the 500 running simulations. The room dimensions and orientation are also a constant of 2.75-meter wall height, $6.75 \times 6.75$ meter floor, and roof area, while the room orientation is in west direction at a typical summer day.

\section{METHODOLOGY}

The research focuses on detecting the best angle of rotation around Y-axis for the sun breaker, in order to be used for any residential buildings that have a western facade direction within the range of 4:00 pm in Cairo, Egypt, which is functionally used to decrease the cooling loads and total energy consumption. As known, the climatic conditions in this zone are known all over the year as tropical and subtropical high zones as clarified by Köppen classification. Cairo is located at $30.08^{\circ} \mathrm{N}, 031.24^{\circ} \mathrm{E}$, and lies at a mean elevation of 74 meters from the sea level (Weatherbase 2020).

The research methodology is built on generative design tool of parametric design, Rhinoceros Version 6.0, educational license valid for three months, in addition to Grasshopper plugin with the cooperation of Ladybug and Honeybee and toolbox which are free plugins. Several researchers in different fields have scientifically used this software to measure various environmental aspects for indoor spaces as daylight studies, thermal comfort, and so on (Lagois et al., 2014; Kamel, 2020; and Soflaei et al., 2020).

Ladybug and Honeybee plugin is used for conducting a parametric study of running 500 simulations. These simulations are coming up with solutions for one of residential spaces of a standard proportion. The ladybug is used 
to import and analyze the climatic conditions for a certain zone at any coordination of azimuth and latitude angles by importing Energy Plus Weather (EPW), whereas Honeybee recommends alternatives in design phases using a vitality Energy Plus engine to address any environmental concerns. This engine is used by multidisciplinary engineers in different fields to model both the energy consumption and the water used in building (Energy Plus, 2020)

The below figures show the space dimensions of $6,875 \times 6,875 \times 2,75$ meters, while this ratio is $1: 2,75$ to the ceiling height (State of Victoria, 2016). The Window Wall Ratio (WWR) variation ranges between 10\%, 15\%, 20\%, $25 \%$, and $30 \%$. In addition, the sun breaker range is specifically associated with the window width of $0 \%, 10 \%$, $20 \%, 30 \%, 40 \%$, and $50 \%$.
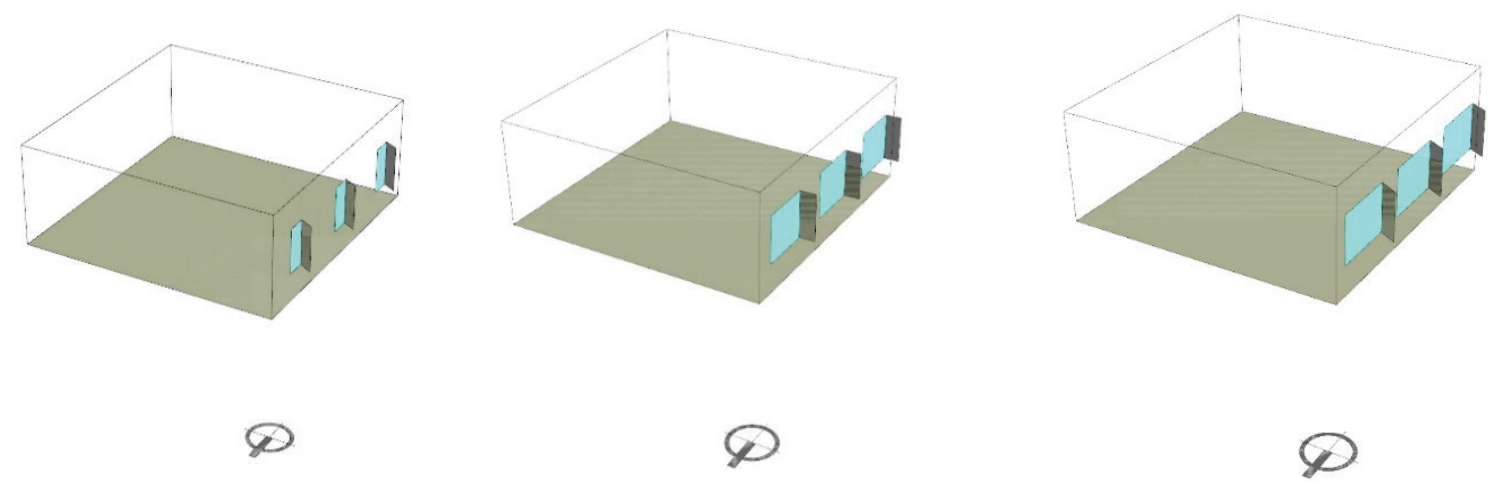

Figure 1. The definition of parametric space varying in WWR, shading depth, and angle of rotation

The main output of the research is to deduce and identify parametric equations for the best angle of rotation for the shading devices around the Y-axis when the residential building Energy Unit Intensity (EUI) $\mathrm{kWh} / \mathrm{m}^{2}$ is compatible with or more stringent with local regulations or ASHRAE 90.1 code. Based on the local energy consumption code for residential buildings, building materials and their thermal properties must be in range or not less than the table below, as stated by the exact values that are used as a constant value during the iterations of each running simulation.

Table 1. Material construction properties and WWR.

\begin{tabular}{|l|c|c|c|}
\hline Point of comparison & R-value (m-K/W) & SHGC & WWR \% \\
\hline Western wall & 0,27 to 0,67 & - & - \\
\hline Roof and ceiling & 1,9 to 2,3 & - & - \\
\hline Windows glass & - & 0,27 to 0,55 & 10 to $30 \%$ \\
\hline Area of windows & & & \\
\hline
\end{tabular}

When comparing the specified building materials of the roof, flooring, wall layers, and type of windows glass in the defined value of the Egyptian national code, the threshold values are, respectively, exceeded. The room usage is scheduled as residential building program as dominated by ASHRAE 90.1, a mid-rise apartment, while using a fan coil air conditioning unit. The tables below stated exactly the input values of the roof, flooring, walls layers, and the windows type. 
Table 2. Construction materials' thermal properties.

\begin{tabular}{|l|l|l|}
\hline Roughness & Medium & Medium \\
\hline Thickness (m) & 0.1241421 & 0.12086 \\
\hline Conductivity (W/m-K) & 0.049 & 0.049 \\
\hline Density (kg/m3) & 265 & 265 \\
\hline Specific heat (J/kg-K) & 836.800 & 836.800 \\
\hline Thermal absorptance & 0.9 & 0.9 \\
\hline Solar absorptance & 0.7 & 0.7 \\
\hline Visible absorptance & 0.7 & 0.7 \\
\hline R-Value & 2.53 & 2.46 \\
\hline
\end{tabular}

Table 3. Windows glass specs.

\begin{tabular}{|l|l|}
\hline Thickness (m) & 0.00051 \\
\hline Solar transmittance at normal incidence & 0.656 \\
\hline Front side solar reflectance at normal incidence & 0.249 \\
\hline Back side solar reflectance at normal incidence & 0.227 \\
\hline Visible transmittance at normal incidence & 0.868 \\
\hline Front side visible reflectance at normal incidence & 0.064 \\
\hline Back side visible reflectance at normal incidence & 0.060 \\
\hline Infrared transmittance at normal incidence & 0.0 \\
\hline Front Sse infrared hemispherical emissivity & 0.136 \\
\hline Back side infrared hemispherical emissivity & 0.720 \\
\hline Conductivity (W/m-K) & 0.14 \\
\hline SHGC & 0.39 \\
\hline
\end{tabular}

The grasshopper script is divided into five successive stages, as shown in the figure below. First and second stages are the space definition of room dimensions in X, Y, Z, space usage type, and the thermal properties of each construction material. Stage three is calculating the space, energy consumption in cooling loads, and total EUI, using engine, Energy Plus. Radiance and Daysim, two calibrated engines, are used to measure the light intensity in Lux during the fourth stage. The most critical part is the fifth stage. During this phase, Colibri is used, creating the parametric definition for various inputs of WWR percentage, shading depth, the angle of rotation, and testing each variable when the others are constant. 


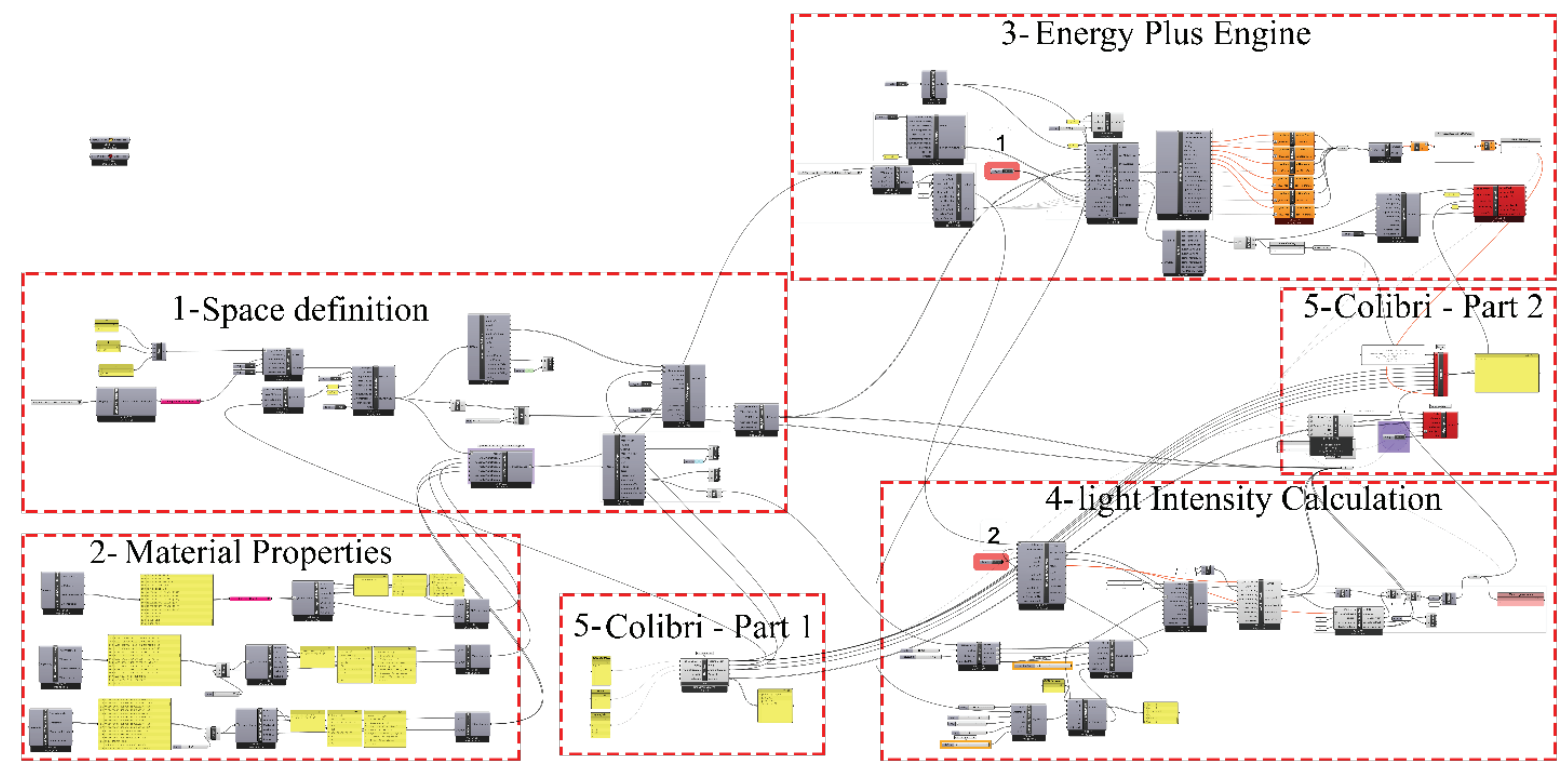

Figure 2. The Comprehensive parametric definition in Grasshopper for calculating the energy consumption of Cooling Loads and total EUI.

\section{RESULTS AND DISCUSSION}

\section{Parameter Study Scheme}

Design Explorer Lite is an open-source website, which is used to compare the Ladybug and Honeybee output simulations. It can also show how the parameters can affect the EUI resulting from their WWR percentage changes, rotation angle around the $\mathrm{Y}$-axis, and shading depth. Five hundred iterations are generated from different scenarios, with each scenario, having a different platform data to compare and deduce the result. The figure below is a print screen of the output results using Design Explorer Lite website.
$\leftarrow \rightarrow C$ 苗
(1) O https:/tt-acm.github.io/DesignExplorer/
目 $\cdots \otimes$ 的
III $₫ \odot \equiv$

\section{[]DesignExplorer Getoata}

1. Reset Selection Exclude Selection Zoom to Selection Save Selection to File My Static Link Tutorial Services Info

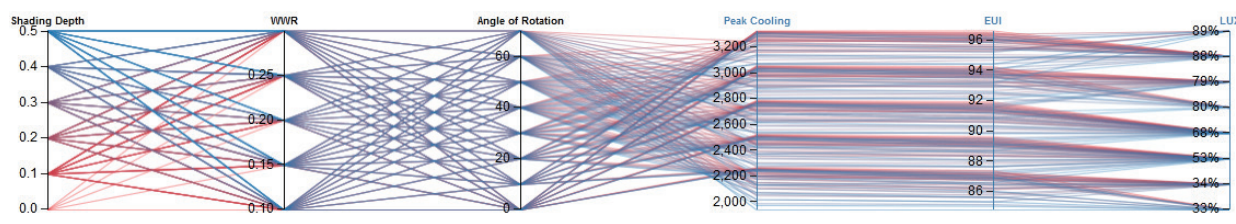

Sort by: Shading Depth $: 0$

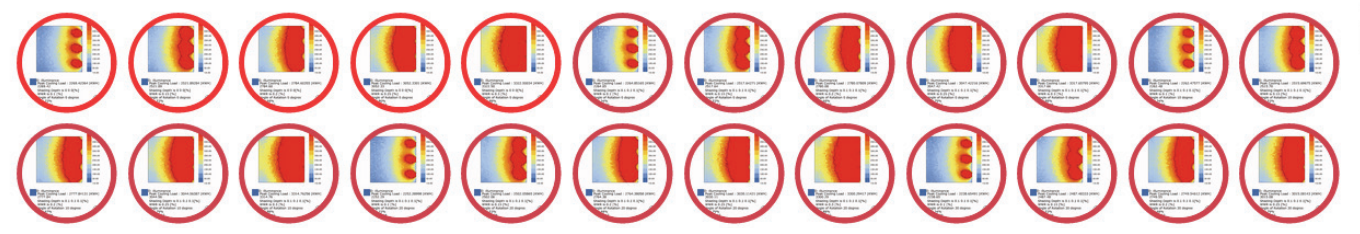

Figure 3. Design Explorer Lite web page print screen. 


\section{Effect of WWR, Shading Depth, and Angle of Rotation on Peak Cooling Load}

One of the main inputs for the Grasshopper plugin is the type of air conditioning; the one used is the fan coil unit, as it is the most common indoor air-cooling device in the residential building in Egypt. The Energy Plus zone thresholds for cooling and heating set back are $24{ }^{\circ} \mathrm{C}$, and $21{ }^{\circ} \mathrm{C}$, respectively. The measurements and calculations of the fan coil unit take into consideration how much energy the sun's rays take to heat up the room space either through the windows or walls or roofs or the surrounding spaces. The space is modeled as the local code requirements for the U \& R-Values of any building construction material in order to minimize the energy gain from the sun's rays, and the below figures are sample of the running simulations.

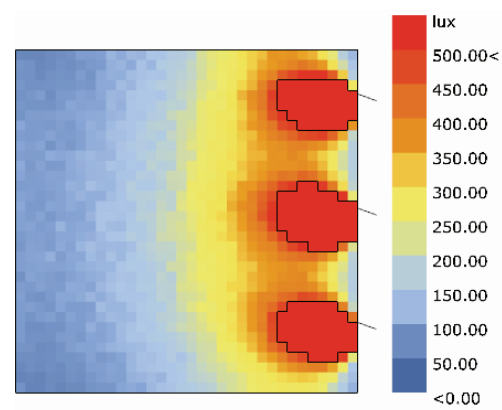

0 : illuminance

Peak Cooling Load : 2208.73125 [KWH]

2208.73

Shading Depth is $0.40 .40 .4[\%]$

WWR is 0.1 [\%]

Angle of Rotation 20 degree

LUX 34\%

EUI 86.61

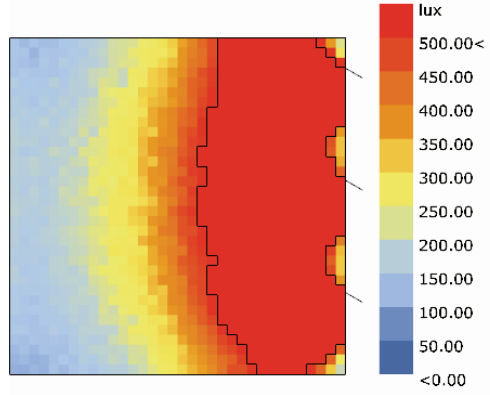

0 : illuminance

Peak Cooling Load : 2645.1743 [KWH]

2645.17

Shading Depth is $0.40 .40 .4[\%]$

WWR is 0.2 [\%]

Angle of Rotation 30 degree

LUX $68 \%$

EUI 90.58

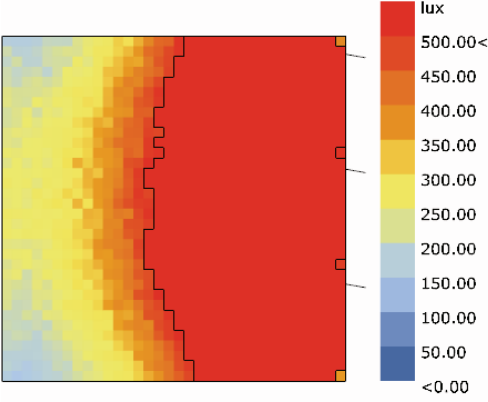

0 : illuminance

Peak Cooling Load : 3287.52452 [KWH]

3287.52

Shading Depth is $0.40 .40 .4[\%]$

WWR is 0.3 [\%]

Angle of Rotation 10 degree

LUX 89\%

EUI 95.93

Figure 4: Several output simulations with various data input.

The charts below depend on the cooling load output. At the same time, this peaking cooling load is considered to be a dependent variable, while the WWR percentage, shading depth, and angle of rotation are considered as the independent variables. So each parameter can affect the cooling load results either by increasing or decreasing the value in $\mathrm{kWh} / \mathrm{m}^{2}$. The charts are addressing the correlation between eight angles of rotation around the $\mathrm{Y}$-axis, increasing in WWR \% with the increase of sun breaker depth, consequently, in which the WWR is $10 \%, 15 \%, 20 \%$, $25 \%$, and $30 \%$, while sun breaker is $10 \%, 20 \%, 30 \%, 40 \%$, and $50 \%$ of the window's width. Also, they are discussing the impact of changing each parameter on their cooling load results and demonstrating the impact of increasing the angle of rotation of sun breakers around $Y$-axis varying degrees of $0^{\circ}, 10^{\circ}, 20^{\circ}, 30^{\circ}, 40^{\circ}, 50^{\circ}, 60^{\circ}$, and $70^{\circ}$, when the WWR \% is constant for each group separately, and sun breaker itself increases gradually from $10 \%$ to $50 \%$ of the window's width. It is concluded that the more increase in angle of rotation, the more the loss in cooling load output value, and this is logic, because the space is more shaded with less heat gain from the sun's rays. On the other side, it is less in exposing to outdoor space views. However, the cooling load is increasing in repetitive increment value, $250 \mathrm{kWh} / \mathrm{m}^{2}$, when the WWR is increasing by $5 \%$ in each group of running simulation. 


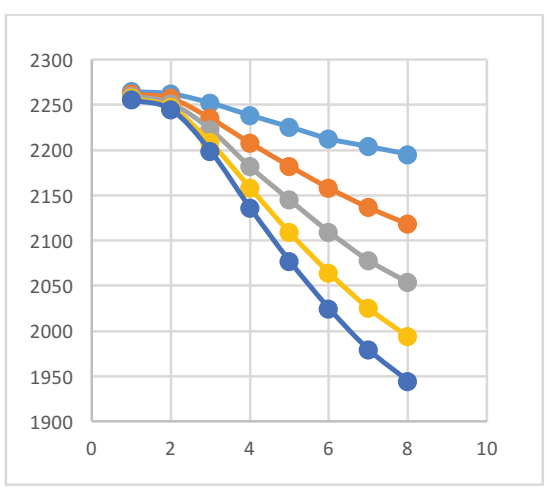

Graph (1). A correlation between WWR of $10 \%$ with gradual increment of $10^{\circ}$ angle of rotation and shading depth of $10 \%$ of windows ' width

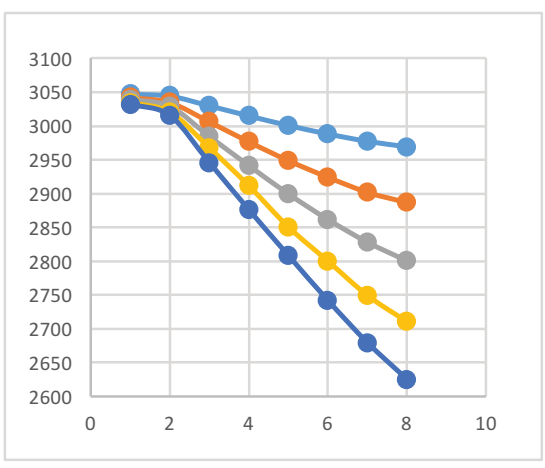

Graph (4): A correlation between WWR of $25 \%$ with gradual increment of $10^{\circ}$ angle of rotation and shading depth of $10 \%$ of windows ' width

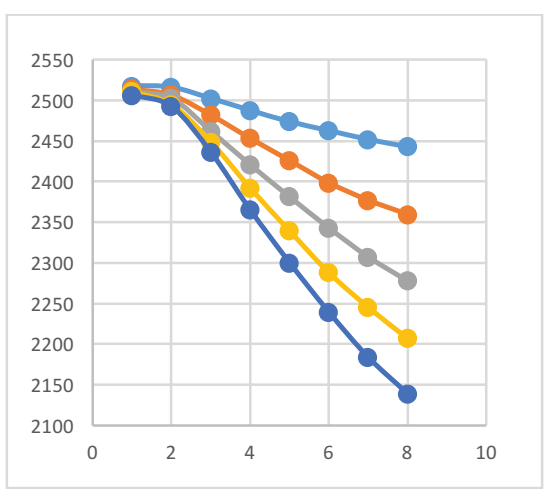

Graph (2): A correlation between WWR of $15 \%$ with gradual increment of $10^{\circ}$ angle of rotation and shading depth of $10 \%$ of windows` width

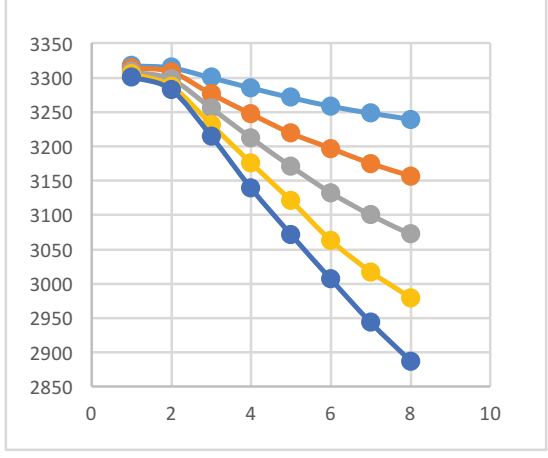

Graph (5): A correlation between WWR of $30 \%$ with gradual increment of $10^{\circ}$ angle of rotation and shading depth of $10 \%$ of windows` width

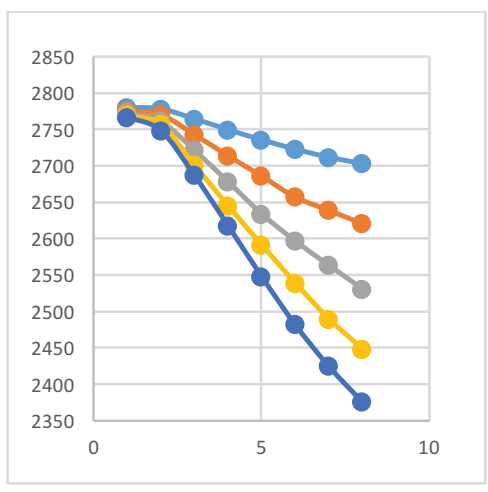

Graph (3): A correlation between WWR of $20 \%$ with gradual increment of $10^{\circ}$ angle of rotation and shading depth of $10 \%$ of windows` width

This is not all, the sun breaker rotation angle base case of zero degree is compared as prescribed by the Egyptian local code for residential buildings, the greater the rotation angle, the greater the effect to minimize the heat emitted and gained by the sun's rays. Furthermore, as the rotation angles are comparative to each other, as shown in the charts below, the peak reduction in cooling load reaches to $30^{\circ}$ of angle of rotation around Y-axis for all WWR percentages, despite that the interest is increasing slowly. 


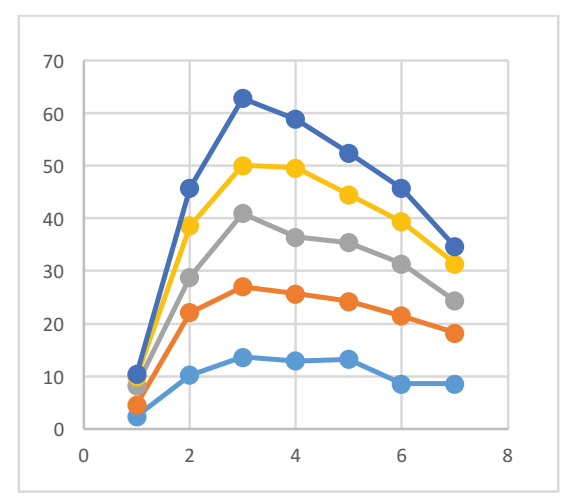

Graph (6). The difference in cooling loads as the sun breaker rotates $10^{\circ}$, repetitively, when the WWR is $10 \%$.

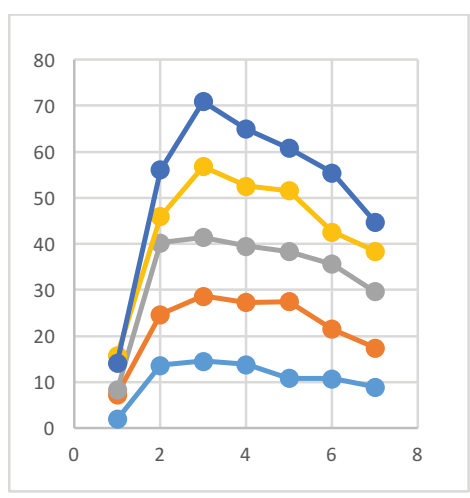

Graph (7). The difference in cooling loads as the sun breaker rotates $10^{\circ}$, repetitively, when the WWR is $15 \%$.

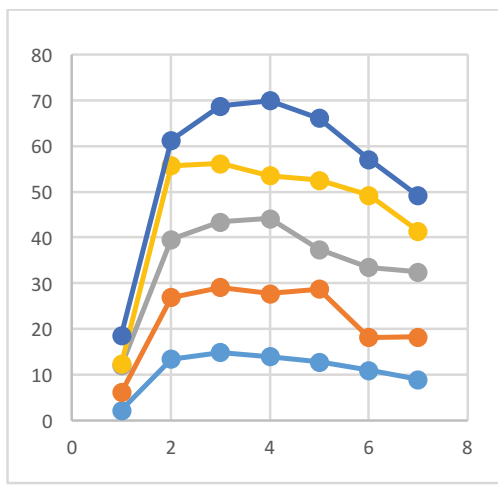

Graph (8). The difference in cooling loads as the sun breaker rotates $10^{\circ}$, repetitively, when the WWR is $20 \%$.

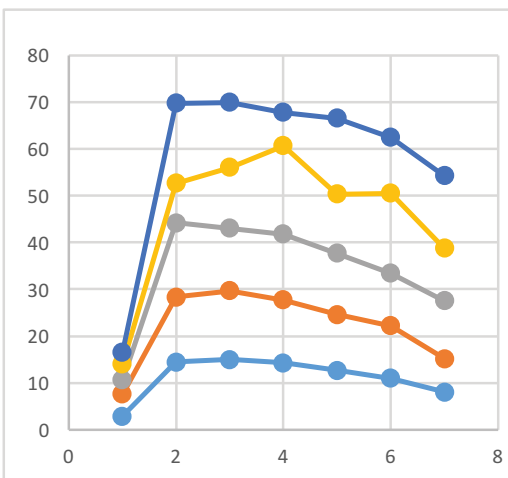

Graph (9). The difference in cooling loads as the sun breaker rotates $10^{\circ}$, repetitively, when the WWR is $25 \%$.

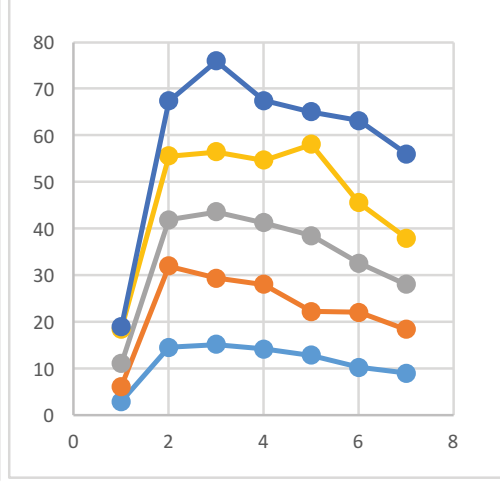

Graph (10). The difference in cooling loads as the sun breaker rotates $10^{\circ}$, repetitively, when the WWR is $30 \%$.

\section{DESIGN RULES}

Energy Use Intensity (EUI) is determined by measuring the overall energy consumption of a given area for one year to be divided by the total gross floor area in $\mathrm{kWh} / \mathrm{m}^{2}$ (Energy Star 2020). EUI requires multiple sources to deduce and calculate the indoor energy consumption, including air conditioning, heaters, and television. The scheduled usage for each appliance shall be calculated and presumed by ASHRAE 90.1 of about $147.098 \mathrm{kWh} / \mathrm{m}^{2}$.

Two linear regression equations are derived from this valuable study through running 500 simulations with the help of Grasshopper plugin. The equations primarily depend mainly on the EUI value, and this value is affected by several independent variables of light intensity, sun breaker depth, and Window Wall Ratio. The two equations express the weight of each parameter and their values in increasing or decreasing the percentage value of the EUI. 
All of these studies and strategies can help architects or any discipline to check and test the EUI percentage value prior to on-site implementation. As stated in the earlier paragraphs and analysis, the most acceptable rotation angle around the $\mathrm{Y}$-axis is approximately $30^{\circ}$, as the lowest value of the heat generated and emitted from sun 's rays was reported. Thus, Equations (1) and (2) describe the effect of using a higher reflective material than a matte one. Equation (1) is a matte, and Equation (2) is a standard non-reflective material.

Equation (1): RAD $0=83.93+50.25 \mathrm{WWR} \%$ - 3.47 shading depth \%- 0.02 angle of rotation in degree- 1.94 light intensity in Lux

Equation (2): RAD 1=83.93+49.59WWR\% - 3.48 shading depth \% - 0.02 angle of rotation in degree- 1.54 light intensity in Lux

As a consequence, a new input was added to these equations, which is the light intensity in Lux. It seems that after measurements the difference and variation between the two materials will increase in the range between 4 and 10 lux. $\mathrm{R}^{2}$ in both equations is 0.99 , which is almost 1 , while the P-values are less than 0.05 . All these values can prove that the correlation between the parameters has a good and strong relationship, and each variable totally depends on the other, and the alter in one parameter could affect the output result.

\section{CONCLUSION}

Both energy crisis and sustainable development obstacles are trying to find a way out, having enormous wealth of existing non-renewable energy resources, virgin materials, and economic growth for the upcoming generations. After COVID 19, the earth and its atmosphere layers took a deep pure breath without any impurities and solid particles. Most of the environmental issues were over, the ozone hole was healed, and ecosystems were back to nature, and so on.

The housing sector is usually the one with the highest energy consumption of non-renewable resources like coal, benzene, and so on. And this is due to a period longer than 24-hour occupation of indoor residential buildings. Air conditioning is sharing the greatest power consuming compare to other appliances. As usual, fan coil unit is used regardless of the type of housing either of middle or low income. The only controllable feature is the setback degrees of both cooling and heating; this element can help in reducing the fan spin and electricity usage.

Sun breaker or shading device is a simple passive system technique, used to permit or reduce the sun`s ray emission of heat for the indoor spaces. Egyptian heritage buildings usually used the wooden Mashrabiya of a perforated surface of various sizes in areas. Such holes become narrower with smaller openings as we step to the window ledge, and adding the bad conductor material of wood can aid in preventing the transmission of the heat gained from the sun to be in touch with indoor air layers.

The research hypothesis seems right; the dynamic louvers are more effective and powerful than the static ones in cooling loads reduction, but the rotation angle around Y-axis had a peak of rotational degree. By testing and simulation, it is deduced that the most appropriate angle is $30^{\circ}$, as the more the angle of rotation, the less the effect in energy reduction. Two linear regression equations are used to match the threshold or less for the $\mathrm{EUI} \mathrm{kWh} / \mathrm{m}^{2}$ as it is prescribed in or more stringent either in ASHRAE 90.1 or local Egyptian code. That is not all, the fabricated material for the sun breaker had a great impact on light intensity for the indoor spaces, as the more reflective the material, the lighter the intensity, and vice versa. 


\section{REFERENCES}

As of August 25, 2020, theDeutsche Wellelistedonitswebsitehttps://www.dw.com/en/record-size-ozone-holeover-arctic-now-healed-and-closed/a-53304374.

As of August 25, 2020, the Carbon Brief listedonitswebsitehttps://www.carbonbrief.org/analysis-coronavirusset-to-cause-largest-ever-annual-fall-in-co2-emissions.

As of August 25, 2020, the British Broadcasting base listedonitswebsitehttps://www.bbc.com/news/scienceenvironment-52485712.

Booth, Colin, Hammond, Felix, Lamond, and Jessica 2014. "Solutions for Climate Change Challenges in the Built Environment" John Wiley and Sons Inc.

Lagios K., NiemaszJ., and Reinhart C. F. 2010. “Animated Building Performance Simulation (ABPS)-Linking Rhinoceros/Grasshopper with Radiance/Daysim SimBuild”, New York City. USGBC2014. "Reference Guide for Building Design and Construction V4", Washington, DC.

Li D. H., and Tsang E. K. 2008. "An Analysis of Daylighting Performance for Office Buildings in Hong Kong” Building and Environment.

Dubois M.C. 1997. "Solar shading and building energy use: A literature review, part I. Report TABK97/3049. Lund Inst. of Technology, Dept. of BuildingScience, LundSweden."

Marsh A. 2003. "Computer-Optimized Shading Design: Eighth International IBPSA Conference Eindhoven, Netherlands."

Olgyay, A., and Olgyay V. 1957. "Design with Climate: Solar Control \& Shading devices” New Jersey: Princeton University Press.

("As of August 25, 2020, the Weather base listedonitswebsitehttps://www.weatherbase.com/weather/weather.php3?s=66326\&cityname $=\mathrm{Cairo} \% 2 \mathrm{C}+\mathrm{M}$ uhafazat+al+Qahirah\%2C+Egypt").

Kamel, T. 2020. “The Econometric Impacts of LEED Certified Building."International Conference: THE PATH TO CITY RESILIENCE. Cairo - EGY: MSA

Soflaei, F., Shokouhian, M., Tabadkani, A., Moslehi, H., \& Berardi, U. 2020. "A simulation-based model for courtyard housing design based on adaptive thermal Comfort." Journal of Building Engineering, doi:https://doi.org/10.1016/j.jobe.2020.101335

State of Victoria 2016. “Better Apartments Design Standards.” Victoria State Government.

As of August 25, 2020, the Energy Plus listedonitswebsitehttps://energyplus.net/.

As of August 25, 2020, the Energy Star listedonitswebsitehttps://www.energystar.gov/buildings/facility-ownersand-managers/existing-buildings/use-portfolio-manager/understand-metrics/what-energy". 